\title{
Ascending aorta aneursym with chronic type a dissection
}

\begin{abstract}
Abdominal aortic aneurysm is the most common type of aortic aneurysms. Thoracic aortic aneurysm is the most insidious until growing up to developing clinical dissection. Early diagnosis and treatment prevent against to deadly consequences..In this case it was wanted to emphasize the importance of multimodality imaging.
\end{abstract}

Keywords: aortic aneurysm, aortic dissection, multimodality imagining
Volume 8 Issue 6 - 2017

\author{
Emine Altunta?,' Songül Usalp, ${ }^{2}$ Yasemen \\ Durak, ${ }^{3}$ Ertan Sa?ba?, ${ }^{4}$ Levent Onat, ${ }^{5}$ Nurcan \\ Arat $^{6}$ \\ 'Cardiology, Zonguldak Atat \\ ${ }^{2}$ Cardiology, Tokat, Turhal State Hospital,Turkey \\ ${ }^{3}$ Cardiovascular Surgery, ?anl?urfa, Mehmet Akif Inan Research \\ and Training Hospital, Turkey \\ ${ }^{4}$ Cardiovascular Surgery, Florence Nightingale Hospital, Turkey \\ ${ }^{5}$ Radiology, Florence Nightingale Hospital, Turkey \\ ${ }^{6}$ Cardiology, Florence Nightingale Hospital, Turkey
}

Correspondence: Emine Altunta?, Hospital Cardiology Department, Zonguldak State Zonguldak, Turkey, Tel +90 053465658 82, Email emine_altuntas@hotmail.com

\section{Introduction}

Aortic aneurysm is a pathology that occurs with a 1.5 fold dilatation of aortic normal diameter.1 Aortic dissection results in that high arterial pressure decomposes to aortic layers. The main reason is the sudden pressure increase in the unit when the increased 'shear' force along the aortic lumen leads to aortic luminal cardiac systole. 2 Aortic aneurysm can be confronted with a wide spectrum of fatal or incidental clinical consequences. Many patients are asymptomatic. Most common etiological risk factors of aortic aneursym are uncontrolled hypertension and senility. Other etiological risk factors are smoking, dyslipidemia, Marfan syndrome, other collagen tissue diseases, infections, inflamations, trauma, cystic medial necrosis. We represent here that a case diagnosed with giant ascending aortic aneursym when she was examined with dyspnea.

\section{Case presentation}

A 62-year-old female patient with known hypertension, obesity history was referred to the cardiology polyclinic by inhalation and diuretic therapy after examination of her chest diseases polyclinic with shortness of breath and rapid fatigue. Blood pressure was measured $130 / 80 \mathrm{mmHg}$ in both of arm, pulse was $114 / \mathrm{m}$ and irregular. Periferal pulses were fuller, faster, arrhtymic on all extremity. Heart sounds were heard as a $3 / 6$ diastolic murmur in aortic focus and 2/6 systolic murmur in mitral focus. Respiratory sounds were normal and equal in both of hemithorax. Hyperlipidemia, impaired fasting glucose, normal renal function were detected in laboratory tests. In echocardiographic examination was revealed ejection fraction $\% 32$, mild mitral and tricuspid regurgitation, modarete aortic regurgitation and degeneration at both of valves, aneurismatic dilatation in ascending aorta $(9.1 \mathrm{~cm})$ and aortic arch $(5.4 \mathrm{~cm})$ were revealed (Figure 1). There was seen dissection fleb in proximal ascending aorta and thrombus was observed in false lumen. Afterwards, that patient was scaned by thoracoabdominal computerized tomography angiography. Diameter of aneursym was measured $9.8 \mathrm{~cm}$ and it was extending to the arch aorta (Figure $2 \& 3$ ). Dissection and plaque were not seen on carotid doppler ultrasonography. Coronary angiography was not applied to patient before surgery operation because of high risk. Supracoronary Graft Interposition and Hemiarchus Replacement was applied to patient after preparations were completed (Figure 4 \& 5). Prostetic aortic valve replacment was not performed to patient because of there was no pathology other than degeneration. Control echocardiography was performed after intensive care process. Ejection fraction was measured $\% 55$ and seen mild mitral-aortic-tricuspid regurgitation. The patient was discharged after 6 days without any problems in the postoperative period.

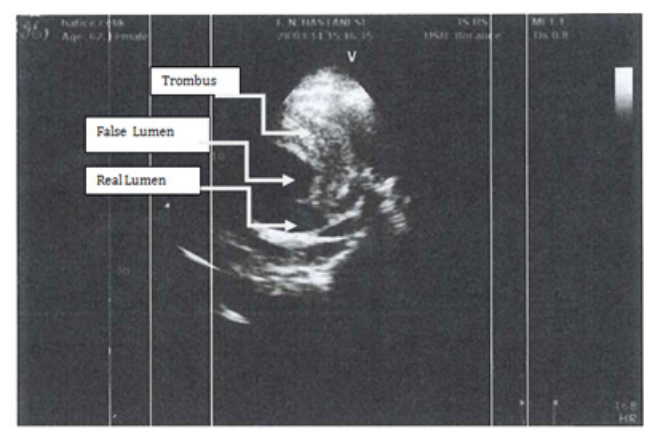

Figure I Echocardiographic image of ascending aorta aneursym with chronic type a dissection.

\section{Discussion}

Even though abdominal aortic aneursym is seen the most frequently, thoracic aortic aneursym have different importance because of it is quite as development of rupture and dissection clinic. Early diagnosis and treatment prevent from mortality. In the recently published European Cardiology Society Guide to Aortic Diseases (2014) surgical borders are as follows; $45 \mathrm{~mm}$ in patients with Marfan's syndrome, $50 \mathrm{~mm}$ in patients with bicuspid aortic valve and $55 \mathrm{~mm}$ in the other patient group. ${ }^{4}$ In our patient, the diameter of ascending aorta was measured as $98 \mathrm{~mm}$ in the widest place. Thoracic $\mathrm{CT}$ angiography provides us with the most accurate results in terms 
of assessing how far and where the aneurysm has been measured and how far it has been measured, even though echocardiography is required routine evaluation in outpatient. We also want to emphasize the importance of multimodality imaging in this case.

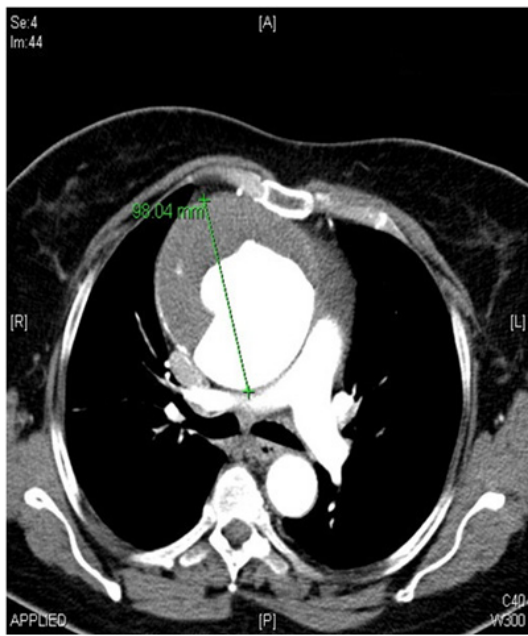

Figure 2 Computerized Tomography Angiography Image of Ascending Aort Aneursym with chronic dissection.

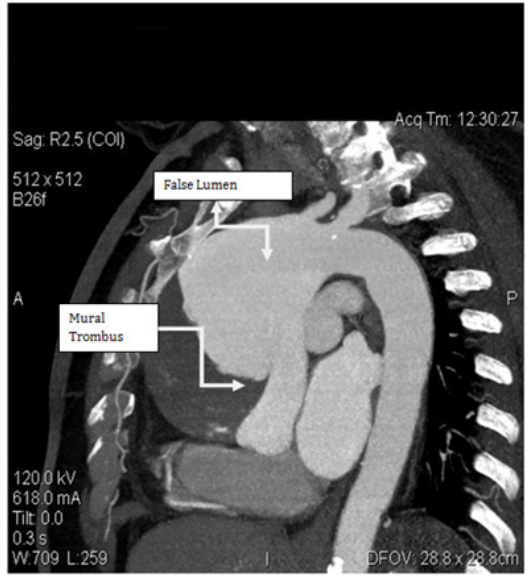

Figure 3 Computerized Tomography Angiography Image of Ascending Aort Aneursym with chronic dissection.

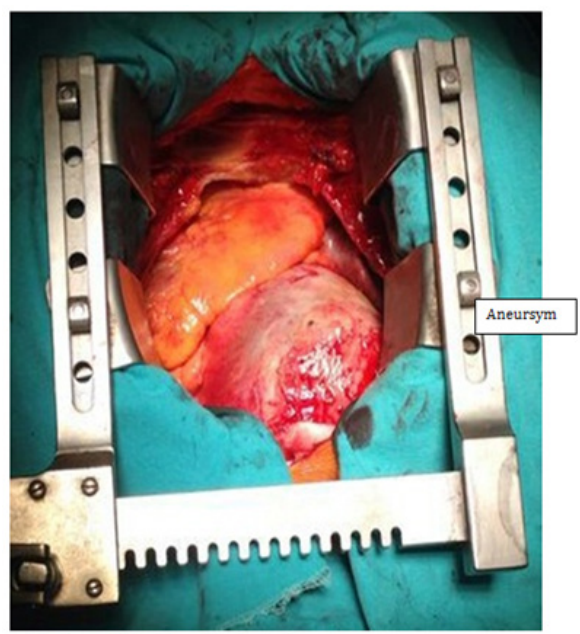

Figure 4 Operation Image of Giant Ascending Aorta Aneursym.

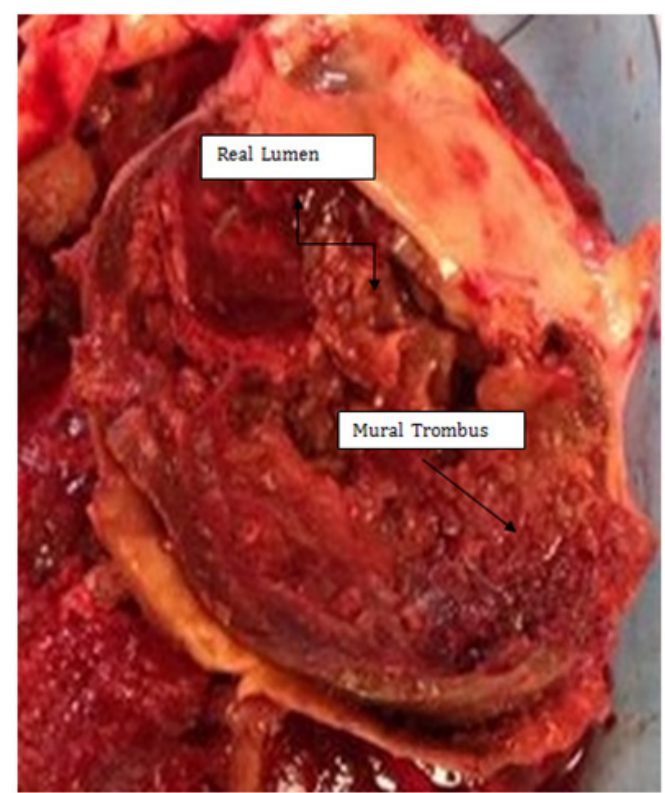

Figure 5 Piece İmage of Giant Ascending Aorta Aneursym.

\section{Acknowledgments}

None.

\section{Conflicts of interest}

Author declares there are no conflicts of interest.

\section{Funding}

None.

\section{References}

1. Brian P Griffin, Thomas D Callahan, Venu Menon. Manuel of Cardiovascular Medicine (4th edn). 2013. p.74-478.

2. Donovan EM, Seidel GK, Cohen A. Painless aortic dissection presenting as high paraplegia: a case report. Arch Phys Med Rehabil. 2000;81:1436-1438

3. Robert O Bonow, Douglas L Mann, Peter LibbyBraunwald's Heart Disease (9th edn). 2013. p.1314-1320.

4. Jose Luis Zamorano, Stephan Achenbach, Helmut Baumgartner . Aortic Disease Guidelines, European Cardiology Society. 2004. 